\title{
REALISASI SISTEM LINIER INVARIANT WAKTU
}

\author{
ANGGI SYAPUTRA \\ Program Studi Matematika, \\ Fakultas Matematika dan Ilmu Pengetahuan Alam, Universitas Andalas, \\ Kampus UNAND Limau Manis Padang, Indonesia, \\ chova_putra91@yahoo.co.id
}

\begin{abstract}
Abstrak. Dalam penelitian ini akan dibahas mengenai realisasi sistem linier invariant waktu. Permasalahannya adalah menentukan matriks $A, B$, dan $C$ dari suatu fungsi tranfer $G(s)$ yang diberikan di mana fungsi transfernya adalah stricly proper. Matriks $A$, $B$ dan $C$ adakalanya tidak unik. Dalam penelitian ini juga dibahas permasalahan realisasi minimal untuk mengetahui apakah suatu matriks $A, B$ dan $C$ unik atau tidak. Suatu contoh diberikan untuk mengilustrasikan realisasi dan realisasi minimal dari sistem linier invariant waktu.
\end{abstract}

Kata Kunci: Fungsi transfer strictly proper, realisasi, realisasi minimal

\section{Pendahuluan}

Misalkan diberikan sistem persamaan linier invariant waktu dalam bentuk,

$$
\begin{aligned}
\dot{\mathbf{x}}(t) & =A \mathbf{x}(t)+B \mathbf{u}(t) \\
\mathbf{y}(t) & =C \mathbf{x}(t) .
\end{aligned}
$$

di mana $\mathbf{x}(t) \in \mathbb{R}^{n}, \mathbf{u}(t) \in \mathbb{R}^{m}, \mathbf{y}(t) \in \mathbb{R}^{p}, A \in \mathbb{R}^{n \times n}, B \in \mathbb{R}^{n \times m}, C \in \mathbb{R}^{p \times n}$, dengan variabel $\mathbf{x}$ menyatakan variabel keadaan, variabel $\mathbf{u}$ menyatakan variabel kontrol(input) dan variabel $\mathbf{y}$ menyatakan variabel output. Dalam beberapa literatur, sistem (1.1) disebut sebagai representasi ruang keadaan dari sistem kontrol linier invariant waktu [5].

Fungsi Transfer suatu sistem linear dinotasikan dengan $G(s)$, didefinisikan sebagai perbandingan transformasi Laplace sinyal output terhadap sinyal input dengan asumsi semua kondisi awal sama dengan nol, yaitu

$$
\mathbf{Y}(s)=G(s) \mathbf{U}(s),
$$

di mana $\mathbf{Y}(s)=£\{\mathbf{y}(t)\}$ dan $\mathbf{U}(s)=£\{\mathbf{u}(t)\}$. Fungsi transfer untuk sistem di atas adalah

$$
G(s)=C(s I-A)^{-1} B .
$$

Dalam penelitian ini akan dikaji permasalahan realisasi dari suatu sistem linier invariant waktu, yaitu jika diberikan suatu fungsi transfer $G(s)$, bagaimana bentuk representasi ruang keadaannya yang berkaitan dengan bentuk matriks $A, B, C$ dari representasi ruang keadaan tersebut. Jika matriks $A, B, C$ dapat ditentukan, maka 
realisasi dari fungsi transfer $G(s)$ dinotasikan dengan $\{A, B, C\}$. Adakalanya realisasi $\{A, B, C\}$ yang diperoleh tidak unik, sehingga dapat dicari realisasi minimal dari $\{A, B, C\}$, yaitu matriks $A$ yang berdimensi terkecil [3].

\section{Realisasi Sistem Linier Invariant Waktu}

Pada bab ini akan dibahas mengenai realisasi model ruang keadaan dari matriks fungsi transfer untuk sistem linier invariant waktu Multi Input Multi Output. Model ruang keadaan untuk persoalan ini mempunyai bentuk sebagai berikut.

$$
\begin{aligned}
\dot{\mathbf{x}}(t) & =A \mathbf{x}(t)+B \mathbf{u}(t) \\
\mathbf{y}(t) & =C \mathbf{x}(t) .
\end{aligned}
$$

di mana

$$
\mathbf{x}(t)=\left[\begin{array}{c}
x_{1}(t) \\
x_{2}(t) \\
\vdots \\
x_{n}(t)
\end{array}\right], \quad \mathbf{y}(t)=\left[\begin{array}{c}
y_{1}(t) \\
y_{2}(t) \\
\vdots \\
y_{p}(t)
\end{array}\right] \text { dan } \mathbf{u}(t)=\left[\begin{array}{c}
u_{1}(t) \\
u_{2}(t) \\
\vdots \\
u_{m}(t)
\end{array}\right]
$$

Realisasi model ruang keadaan dapat dikontruksi dari sebarang matriks fungsi transfer yang strictly proper, yaitu matriks fungsi transfer di mana entri-entri dari matriks fungsi transfer memiliki polinomial numeratornya berderajat lebih kecil dari pada polinomial denumeratornya [3].

Teorema 2.1. [3] Diberikan suatu matriks fungsi transfer $G(s)$. Realisasi dari $G(s)$ ada jika dan hanya jika $G(s)$ adalah strictly proper.

Bukti. $(\Leftarrow)$ Misalkan $G(s)$ merupakan matriks fungsi transfer strictly proper, yaitu polinomial numeratornya berderajat lebih kecil dari polinomial denumeratornya untuk setiap entri $g_{i j}$, sebagaimana dapat ditulis

$$
\begin{aligned}
G(s) & =\frac{s^{n-1} N_{n-1}+s^{n-2} N_{n-2}+\cdots+s N_{1}+N_{0}}{s^{n}+d_{n-1} s^{n-1}+\cdots+d_{1} s+d_{0}} \\
& =\frac{1}{d(s)}\left[\begin{array}{llll}
N_{0} N_{1} \cdots N_{n-2} N_{n-1}
\end{array}\right]\left[\begin{array}{c}
I_{m} \\
s I_{m} \\
s^{2} I_{m} \\
\vdots \\
s^{n-1} I_{m}
\end{array}\right] .
\end{aligned}
$$

di mana $d(s)=s^{n}+d_{n-1} s^{n-1}+\cdots+d_{1} s+d_{0}$ dan $N(s)=N_{n-1} s^{n-1}+N_{n-2} s^{n-2}+$ $\cdots+N_{1} S+N_{0}$ serta $N_{0}, N_{2}, \cdots, N_{n-1}$ adalah matriks berukuran $p \times m$.

Definisikan,

$$
\mathbf{Z}(s)=(s I-A)^{-1} B=\frac{1}{d(s)}\left[\begin{array}{c}
I_{m} \\
s I_{m} \\
s^{2} I_{m} \\
\vdots \\
s^{n-1} I_{m}
\end{array}\right]=\left[\begin{array}{c}
Z_{1} \\
Z_{2} \\
\vdots \\
Z_{n-1} \\
Z_{n}
\end{array}\right]
$$


Berdasarkan persamaan (2.4), diperoleh

$$
Z_{1}=\frac{1}{d(s)} I_{m}
$$

dan

$$
\mathbf{Z}_{i+1}=s \mathbf{Z}_{i} \quad i=1,2, \cdots, n-1 .
$$

Dari persamaan (2.5) dan (2.6) diperoleh bahwa

$$
\begin{aligned}
I_{m} & =d_{0} Z_{1}+d_{1} Z_{2}+d_{2} Z_{3}+\cdots+d_{n-1} Z_{n}+s Z_{n}, \\
s Z_{n} & =I_{m}-d_{0} Z_{1}-d_{1} Z_{2}-d_{2} Z_{3}-\cdots-d_{n-1} Z_{n} .
\end{aligned}
$$

Dengan demikian, persamaan (2.7) dapat ditulis menjadi

$$
\left[\begin{array}{c}
s Z_{1} \\
s Z_{2} \\
\vdots \\
s Z_{n-1} \\
s Z_{n}
\end{array}\right]=\left[\begin{array}{cccccc}
0_{m} & I_{m} & 0_{m} & \cdots & 0_{m} & 0_{m} \\
0_{m} & 0_{m} & I_{m} & \cdots & 0_{m} & 0_{m} \\
\vdots & \vdots & \vdots & \vdots & \vdots & \vdots \\
0_{m} & 0_{m} & 0_{m} & \cdots & 0_{m} & I_{m} \\
-d_{0} & -d_{1} & -d_{2} & \cdots & -d_{n-2} & -d_{n-1}
\end{array}\right]\left[\begin{array}{c}
Z_{2} \\
Z_{3} \\
\vdots \\
Z_{n-1} \\
Z_{n}
\end{array}\right]+\left[\begin{array}{c}
0_{m} \\
0_{m} \\
\vdots \\
0_{m} \\
I_{m}
\end{array}\right]
$$

atau dapat juga ditulis

$$
s \mathbf{Z}=A \mathbf{Z}+B
$$

di mana

$$
A=\left[\begin{array}{cccccc}
0_{m} & I_{m} & 0_{m} & \cdots & 0_{m} & 0_{m} \\
0_{m} & 0_{m} & I_{m} & \cdots & 0_{m} & 0_{m} \\
\vdots & \vdots & \vdots & \ddots & \vdots & \vdots \\
0_{m} & 0_{m} & 0_{m} & \cdots & 0_{m} & I_{m} \\
-d_{0} & -d_{1} & -d_{2} & \cdots & -d_{n-2} & -d_{n-1}
\end{array}\right] \quad \text { dan } B=\left[\begin{array}{c}
0_{m} \\
0_{m} \\
\vdots \\
0_{m} \\
I_{m}
\end{array}\right]
$$

Dari persamaan (1.3), diketahui bahwa

$$
G(s)=C(s I-A)^{-1} B .
$$

Berdasarkan persamaan (2.3), maka

$$
\frac{1}{d(s)}\left[N_{0} N_{1} \cdots N_{p-2} N_{p-1}\right]\left[\begin{array}{c}
I_{m} \\
s I_{m} \\
s^{2} I_{m} \\
\vdots \\
s^{p-1} I_{m}
\end{array}\right]=C(s I-A)^{-1} B
$$

di mana

$$
C=\left[\begin{array}{lllll}
N_{0} & N_{1} & \cdots & N_{n-2} & N_{n-1}
\end{array}\right] .
$$

Jadi, diperoleh Matriks $A, B, C$ yang merupakan realisasi dari $G(s)$. 
$(\Rightarrow)$ Misalkan $A, B, C$ merupakan realisasi dari $G(s)$, akan ditunjukkan bahwa $G(s)$ merupakan matriks fungsi transfer yang strictly proper. Perhatikan bahwa,

$$
\begin{aligned}
G(s) & =C(s I-A)^{-1} B \\
& =C\left(\frac{\operatorname{adj}(s I-A)}{\operatorname{det}(s I-A)}\right) B .
\end{aligned}
$$

Karena $\left(\frac{\operatorname{adj}(s I-A)}{\operatorname{det}(s I-A)}\right)$ merupakan matriks yang polinomial denumeratornya berderajat lebih tinggi dari pada polinomial numeratornya untuk setiap entrientrinya, maka matriks fungsi transfer $G(s)$ merupakan matriks fungsi transfer yang strictly proper.

\section{Realisasi Minimal}

Definisi 3.1. [3] Suatu realisasi minimal yang terkait dengan suatu fungsi transfer $G(s)$ adalah suatu model ruang keadaan di mana matriks A berdimensi terkecil.

Teorema 3.2. [3] Suatu Realisasi $\{A, B, C\}$ adalah minimal jika dan hanya jika $\{A, B, C\}$ terkontrol dan terobservarsi.

Bukti. $(\Leftarrow)$ Misalkan realisasi $\{A, B, C\}$ adalah terkontrol dan terobservasi dengan rank dari matriks keterkontrolan dan keterobservasiannya adalah $n$ dan terdapat realisasi lain $\left\{A_{1}, B_{1}, C_{1}\right\}$ dengan rank dari matriks keterkontrolan dan keterobservasiannya adalah $n_{1}$, di mana $n_{1}<n$, sedemikian sehingga realisasi $\{A, B, C\}$ dan $\left\{A_{1}, B_{1}, C_{1}\right\} n_{1}$ mempunyai matriks fungsi transfer yang sama, yaitu

$$
G(s)=C(s I-A)^{-1} B=C_{1}\left(s I-A_{1}\right)^{-1} B_{1} .
$$

Oleh karena itu,

$$
g(t)=C e^{A t} B=C_{1} e^{A_{1} t} B_{1} .
$$

Turunan persamaan (3.2) terhadap $t$ dan dievaluasi pada $t=0$ diperoleh,

$$
C A^{i} B=C_{1} A_{1}^{i} B_{1}, i=1,2, \cdots, n .
$$

Matriks keterkontrolan $M_{c}$ dan matriks keterobservasian $M_{o}$ untuk $\{A, B, C\}$ adalah

$$
M_{c}=\left[\begin{array}{lllll}
B & A B & A^{2} B & \cdots & A^{n-1} B
\end{array}\right] \text { dan } M_{o}=\left[\begin{array}{c}
C \\
C A \\
C A^{2} \\
\vdots \\
C A^{n-1}
\end{array}\right] \text {. }
$$

Perkalian antara $M_{c}$ dengan $M_{o}$ adalah

$$
M_{o} M_{c}=\left[\begin{array}{cccc}
C B & C A B & \cdots & C A^{n-1} B \\
C A B & C A^{2} B & \cdots & C A^{n} B \\
\vdots & \vdots & \cdots & \vdots \\
C A^{n-1} B & C A^{n} B & \cdots & C A^{2 n-2} B
\end{array}\right] .
$$


Matriks keterkontrolan untuk $\left\{A_{1}, B_{1}, C_{1}\right\}$ adalah,

$$
M_{c_{1}}=\left[B_{1} A_{1} B_{1} A_{1}^{2} B_{1} \cdots A_{1}^{n-1} B_{1}\right]
$$

dan matriks keterobservasiannya adalah

$$
M_{o_{1}}=\left[\begin{array}{c}
C_{1} \\
C_{1} A_{1} \\
C_{1} A_{1}^{2} \\
\vdots \\
C_{1} A_{1}^{n-1}
\end{array}\right]
$$

Perkalian dari matriks $M_{o, 1}$ dan $M_{o, 1}$ juga menghasilkan,

$$
M_{o, 1} M_{c, 1}=\left[\begin{array}{cccc}
C_{1} B_{1} & C_{1} A_{1} B_{1} & \cdots & C_{1} A_{1}^{n-1} B_{1} \\
C_{1} A_{1} B_{1} & C_{1} A_{1}^{2} B_{1} & \cdots & C_{1} A_{1}^{n} B_{1} \\
\vdots & \vdots & \cdots & \vdots \\
C_{1} A_{1}^{n-1} B_{1} & C_{1} A_{1}^{n} B_{1} & \cdots & C_{1} A_{1}^{2 n-2} B_{1}
\end{array}\right] .
$$

Berdasarkan (3.3) terlihat bahwa,

$$
M_{o} M_{c}=M_{o, 1} M_{c, 1} .
$$

Karena $\{A, B, C\}$ terkontrol dan terobservasi, maka

$$
\operatorname{rank}\left(M_{o}\right)=\operatorname{rank}\left(M_{c}\right)=n,
$$

yang mengakibatkan

$$
\operatorname{rank}\left(M_{o} M_{c}\right)=n .
$$

Selanjutnya, karena realisasi $\left\{A_{1}, B_{1}, C_{1}\right\}$ terkontrol dan terobservasi, maka

$$
\operatorname{rank}\left(M_{o, 1}\right)=\operatorname{rank}\left(M_{c, 1}\right)=n_{1}
$$

dan mengakibatkan

$$
\operatorname{rank}\left(M_{o_{1}} M_{c_{1}}\right)=n_{1} .
$$

Tetapi, dari persamaan (3.6) diperoleh $n_{1}=n$, yang kontradiksi dengan asumsi bahwa $n_{1}<n$. Dengan kata lain, jika $\{A, B, C\}$ terkontrol dan terobservasi, maka realisasi $\{A, B, C\}$ dikatakan realisasi minimal.

$(\Rightarrow)$ Asumsikan bahwa $\{A, B, C\}$ tidak terkontrol dan tidak terobservasi. Dalam $([2],[3],[7])$ diberikan teorema bentuk standar sistem tidak terkontrol dan tidak terobservasi yang menyatakan bahwa jika $\{A, B\}$ tidak terkontrol dan $\{A, C\}$ tidak terobservasi, maka terdapat realisasi lain dengan fungsi transfer yang sama tetapi derajatnya lebih kecil. Dengan kata lain, jika realisasi $\{A, B, C\}$ adalah minimal, maka $\{A, B, C\}$ terkontrol dan terobservasi.

Contoh 1. Contoh berikut mengilustrasikan bagaimana menentukan realisasi dan realisasi minimal suatu fungsi transfer $G(s)$, di mana

$$
G(s)=\left[\begin{array}{ll}
\frac{s}{(s+1)(s+3)} & \frac{3}{(s+1)(s+3)} \\
\frac{1}{(s+1)(s+3)} & \frac{s+4}{(s+1)(s+3)}
\end{array}\right] .
$$


Matriks fungsi transfer di atas mempunyai dua input dan dua output, sehingga $p=m=2$. Polinomial $d(s)$ harus mengandung semua faktor dari empat polinomial denominator, yaitu

$$
d(s)=(s+1)(s+3)=s^{2}+4 s+3 .
$$

Karena,

$$
0_{m}=\left[\begin{array}{ll}
0 & 0 \\
0 & 0
\end{array}\right] \text { dan } I_{m}=\left[\begin{array}{ll}
1 & 0 \\
0 & 1
\end{array}\right],
$$

Maka matriks $A$ dan $B$ dari realisasi ruang keadaan adalah

$$
A=\left[\begin{array}{cccc}
0 & 0 & 1 & 0 \\
0 & 0 & 0 & 1 \\
-3 & 0 & -4 & 0 \\
0 & -3 & 0 & -4
\end{array}\right], B=\left[\begin{array}{ll}
0 & 0 \\
0 & 0 \\
1 & 0 \\
0 & 1
\end{array}\right]
$$

Perkalian $G(S)$ dengan $d(s)$ menghasilkan,

$$
d(s) G(s)=\left[\begin{array}{cc}
s & 3 \\
1 & s+4
\end{array}\right],
$$

yang dapat ditulis sebagai

$$
\begin{aligned}
d(s) G(s) & =N_{1} s+N_{0} \\
& =\left[\begin{array}{ll}
1 & 0 \\
0 & 1
\end{array}\right] s+\left[\begin{array}{ll}
0 & 3 \\
1 & 4
\end{array}\right],
\end{aligned}
$$

sehingga diperoleh matriks output sebagai berikut,

$$
C=\left[\begin{array}{llll}
0 & 3 & 1 & 0 \\
1 & 4 & 0 & 1
\end{array}\right] .
$$

Dengan menggunakan MATLAB, diperoleh bahwa rank matriks keterkontrolan dari $\{A, B\}$ adalah 4 dan rank matriks keterobservasian dari $\{A, C\}$ adalah 4 , maka $\{A, B\}$ terkontrol dan $\{A, C\}$ terobservasi. Jadi, karena Realisasi $\{A, B\}$ terkontrol dan $\{A, C\}$ terobservasi maka realisasi $\{A, B, C\}$ adalah minimal.

Contoh 2. [5] Diberikan sebuah sistem MIMO LTI dengan matriks fungsi transfer sebagai berikut :

$$
G(S)=\left[\begin{array}{cc}
\frac{1}{(s+1)^{2}} & \frac{3}{s-2} \\
\frac{s+3}{(s+1)(s-2)} & \frac{2}{(s-2)^{2}}
\end{array}\right] .
$$

Akan ditentukan realisasi minimal dari fungsi transfer tersebut.

Matriks fungsi transfer di atas mempunyai 2 input dan 2 output, sehingga $p=m=2$. Polinomial $d(s)$ harus mengandung semua faktor dari 4 polinomial denominator, yaitu

$$
d(s)=(s+1)^{2}(s-2)^{2}=s^{4}-2 s^{3}-3 s^{2}+4 s+4 .
$$


140 Anggi Syaputra

Matriks $A$ dan $B$ dari realisasi ruang keadaan di atas adalah

$$
A=\left[\begin{array}{cccccccc}
0 & 0 & 1 & 0 & 0 & 0 & 0 & 0 \\
0 & 0 & 0 & 1 & 0 & 0 & 0 & 0 \\
0 & 0 & 0 & 0 & 1 & 0 & 0 & 0 \\
0 & 0 & 0 & 0 & 0 & 1 & 0 & 0 \\
0 & 0 & 0 & 0 & 0 & 0 & 1 & 0 \\
0 & 0 & 0 & 0 & 0 & 0 & 0 & 1 \\
-4 & 0 & -4 & 0 & 3 & 0 & 2 & 0 \\
0 & -4 & 0 & -4 & 0 & 3 & 0 & 2
\end{array}\right], B=\left[\begin{array}{ll}
0 & 0 \\
0 & 0 \\
0 & 0 \\
0 & 0 \\
0 & 0 \\
0 & 0 \\
1 & 0 \\
0 & 1
\end{array}\right]
$$

Perkalian $G(s)$ dengan $d(s)$ menghasilkan,

$$
d(s) G(s)=\left[\begin{array}{cr}
s^{2}-4 s+4 & 3 s^{3}-9 s-6 \\
s^{3}+2 s 2-5 s-6 & 2 s^{2}+4 s+2
\end{array}\right],
$$

yang dapat ditulis sebagai,

$$
\begin{aligned}
d(s) G(s) & =N_{3} s^{3}+N_{2} s^{2}+N_{1} s+N_{0} \\
& =\left[\begin{array}{ll}
0 & 3 \\
1 & 0
\end{array}\right] s^{3}+\left[\begin{array}{ll}
1 & 0 \\
2 & 2
\end{array}\right] s^{2}+\left[\begin{array}{cc}
-4 & -9 \\
-5 & 4
\end{array}\right] s+\left[\begin{array}{cc}
4 & -6 \\
-6 & 2
\end{array}\right],
\end{aligned}
$$

sehingga diperoleh matriks output sebagai berikut,

$$
C=\left[\begin{array}{cccccccc}
4 & -6 & -4 & -9 & 1 & 0 & 0 & 3 \\
-6 & 2 & -5 & 4 & 2 & 2 & 1 & 0
\end{array}\right]
$$

Dengan menggunakan MATLAB, diperoleh bahwa rank matriks keterkontrolan dari $\{A, B\}$ adalah 8 dan rank matriks keterobservasian dari $\{A, C\}$ adalah 4 , maka $\{A, B\}$ terkontrol dan $\{A, C\}$ tidak terobservasi.

Jadi, karena realisasi $\{A, B\}$ terkontrol dan $\{A, C\}$ tidak terobservasi maka realisasi $\{A, B, C\}$ bukan realisasi minimal.

Karena Realisasi $\{A, B, C\}$ bukan realisasi minimal, maka untuk menentukan realisasi minimalnya dapat digunakan teorema bentuk standar sistem tidak terobservasi ([2], [3], [7]). Karena rank matriks keterobservasian dari $\{A, C\}$ adalah 4 , maka entri-entri dari empat baris pertama dari matriks keterobservasian sama dengan entri-entri pada empat baris pertama untuk matrik $P$. Pilih entri-entri empat baris berikutnya sedemikian sehingga matriks $P$ adalah non singular.

Misalkan,

$$
P=\left[\begin{array}{cccccccc}
4 & -6 & -4 & -9 & 1 & 0 & 0 & 3 \\
-6 & 2 & -5 & 4 & 2 & 2 & 1 & 0 \\
0 & -12 & 4 & -18 & -4 & 0 & 1 & 6 \\
-4 & 0 & -10 & 2 & -2 & 4 & 4 & 2 \\
1 & 0 & 0 & 0 & 1 & 0 & 0 & 0 \\
0 & 1 & 0 & 0 & 0 & 1 & 0 & 0 \\
0 & 0 & 1 & 0 & 0 & 0 & 1 & 0 \\
0 & 0 & 0 & 1 & 0 & 0 & 0 & 1
\end{array}\right]
$$


Trasnformasi dari persamaan (3.1) memberikan realisasi yang minimal dengan representasi ruang keadaan

$$
\begin{aligned}
\dot{\mathbf{z}} & =A_{0} \mathbf{z}+B_{0} \mathbf{u}, \\
\mathbf{y} & =C_{0} \mathbf{x} .
\end{aligned}
$$

di mana

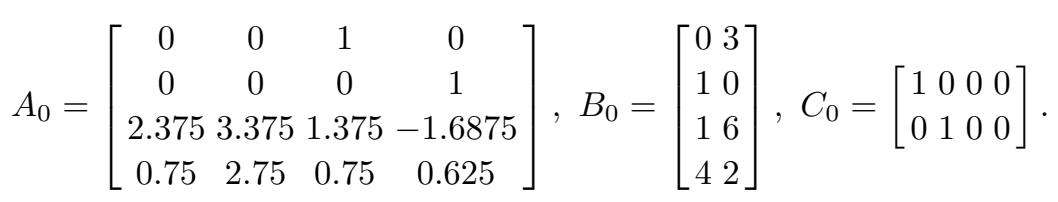

\section{Kesimpulan}

Syarat perlu dan syarat cukup adanya realisasi sistem linier invariant waktu (1.1) adalah fungsi transfer $G(s)$ stricly proper, yaitu polinomial numeratornya berderajat lebih kecil dari pada polinomial denumeratornya.

Realisasi Sistem linier invariant waktu (1.1) dari fungsi transfer $G(s)$ dinotasikan dengan $\{A, B, C\}$. Realisasi $\{A, B, C\}$ adalah minimal untuk suatu model ruang keadaan di mana matriks $A, B$, dan $C$ berdimensi terkecil. Syarat cukup dan syarat perlu realisasi $\{A, B, C\}$ minimal adalah $\{A, B, C\}$ terkontrol dan terobservasi.

\section{Ucapan Terima kasih}

Penulis mengucapkan terima kasih kepada Bapak Dr. Muhafzan, Ibu Arrival Rince Putri, M.T, M.Si, Bapak Dr. Admi Nazra, Ibu Dr. Susila Bahri dan Bapak Efendi, M.Si yang telah memberikan masukan dan saran sehingga paper ini dapat diselesaikan dengan baik.

\section{Daftar Pustaka}

[1] Anton, H. 1991. Aljabar Linier Elementer Edisi Kedelapan-Jilid 1. Penerbit Erlangga, Jakarta.

[2] Antsaklis, Panos J dan Anthony N, Michel. 2007. A Linear Systems Primer . Birkhaäuser, Boston Basel Berlin.

[3] Hendricks,Elbert, Ole Jannerup, Paul Haase Sorensen. 2008. Linear System Control. Springer, Verlag Berlin Heidelberg.

[4] Jacob, Bill. 1990. Linear Algebra. W. H. Freeman and Company, USA.

[5] Ogata, K. 2002. Modern Control Engineering. Prentice-Hall, New Jersey.

[6] Remsing, C.C. 2006. Linear Control

[7] Sinha, Alok. 2007. Linear Systems Optimal and Robust Control. CRC Press, Francis. 